\title{
In vivo tracking of human placenta derived mesenchymal stem cells in nude mice via ${ }^{14} \mathrm{C}-\mathrm{TdR}$ labeling
}

\author{
Cheng-Guang $\mathrm{Wu}^{1}$, Ji-Chun Zhang ${ }^{1}$, Cheng-Quan Xie ${ }^{1}$, Ornella Parolini ${ }^{2}$, Antonietta Silini ${ }^{2}$, Yi-Zhou Huang ${ }^{1}$,
} Bing Lian ${ }^{3}$, Min Zhang ${ }^{4^{*}}$, Yong-Can Huang ${ }^{5^{*}}$ and Li Deng ${ }^{6^{*}}$

\begin{abstract}
Background: In order to shed light on the regenerative mechanism of mesenchymal stem cells (MSCs) in vivo, the bio-distribution profile of implanted cells using a stable and long-term tracking method is needed. We herein investigated the bio-distribution of human placental deciduas basalis derived MSCs (termed as PDB-MSCs) in nude mice after intravenous injection by carbon radioisotope labeling thymidine $\left({ }^{14} \mathrm{C}-\mathrm{TdR}\right)$, which is able to incorporate into new DNA strands during cell replication.

Results: The proliferation rate and radioactive emission of human PDB-MSCs after labeled with different concentrations of ${ }^{14} \mathrm{C}-\mathrm{TdR}$ were measured. PDB-MSCs labeled with $1 \mu \mathrm{Ci}$ possessed high radioactivity, and the biological characteristics (i.e. morphology, colony forming ability, differentiation capabilities, karyotype and cell cycle) showed no significant changes after labeling. Thus, $1 \mu \mathrm{Ci}$ was the optimal concentration in this experimental design. In nude mice, $1 \times 10^{6}$ ${ }^{14} \mathrm{C}$-TdR-labeled PDB-MSCs were injected intravenously and the organs were collected at days 1, 2, 3, 5, 30 and 180 after injection, respectively. Radiolabeled PDB-MSCs were found mainly in the lung, liver, spleen, stomach and left femur of the recipient nude mice at the whole observation period.

Conclusions: This work provided solid evidence that ${ }^{14} \mathrm{C}-\mathrm{TdR}$ labeling did not alter the biological characteristics of human placental MSCs, and that this labeling method has potential to decrease the signal from non-infused or dead cells for cell tracking. Therefore, this labeling technique can be utilized to quantify the infused cells after long-term follow-up in pre-clinical studies.
\end{abstract}

\section{Background}

Mesenchymal stem cells (MSCs) have been regarded as a promising candidate for cell therapy with increasing evidence of improved therapeutic effectiveness in various diseases $[1,2]$. However, the fate and the role of MSCs in disease progression and regression remain largely unclear. In vivo tracking of implanted MSCs will provide a powerful tool to investigate the MSCs-mediated regenerative

\footnotetext{
*Correspondence: tws189@189.cn; y.chuang@connect.hku.hk; dengli2000@ gmail.com

${ }^{4}$ Center Laboratory For Isotopy, West China Hospital, Sichuan University, Chengdu, People's Republic of China

${ }^{5}$ Department of Orthopaedics and Traumatology, The University of Hong Kong, Hong Kong, SAR, People's Republic of China

${ }^{6}$ Laboratory of Stem Cell and Tissue Engineering, State Key Laboratory of Biotherapy, West China Hospital, Sichuan University, Chengdu, People's Republic of China

Full list of author information is available at the end of the article
}

mechanism; especially, the survival, migration and differentiation of MSCs are crucial for successful regeneration. Thus, reliable and quantitative tracking methods to monitor the in vivo bio-distribution of MSCs are highly desirable in animal studies.

Many methods for stem cells tracking are available currently, such as histological detection of xenogeneic or chemical-labeled cells, magnetic resonance imaging scans (MRI), quantum dots (QDs) using fluorescent semiconductor nanocrystals, ultrasound and radiolabeling by nuclear medicine technology [3-8]. Most of them are capable of real-time observation and noninvasive, but the observation time is restricted owing to quick signal strength decline, limiting the accuracy and reliability of experimental results.

Radiolabeled thymidine, such as tritiated thymidine $\left({ }^{3} \mathrm{H}-\mathrm{TdR}\right)$ and ${ }^{14} \mathrm{C}-\mathrm{TdR}$, can be taken up by the

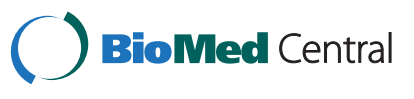


replicating cells and is commonly used for cell cycle analysis to measure the cell proportion at $\mathrm{S}$ phase. Due to the long half-life (12.35 years) and high radioactivity, ${ }^{3} \mathrm{H}-\mathrm{TdR}$ has been used to detect the dynamic distribution of MSCs [9]. Similarly, ${ }^{14} \mathrm{C}$ has a prominent long half-life (about 5730 years) which guarantees the longterm and stably radioactive signal for in vivo detection. Additionally, thymidine labeling in the 2-carbon position can directly degrade into labeled $\mathrm{CO}_{2}$ rather than labeled $\beta$-aminoisobutyric acid or other subsequent metabolites which might be absorbed by the host cells, thus disturbing the accuracy of detection [10-13]. Hence, these advantages of ${ }^{14} \mathrm{C}$ - $\mathrm{TdR}$ ensure its potential application in cell tracking to aid in long-term observation after stem cells grafting.

Human placenta-derived MSCs, similar to those from other sources, possess in vitro differentiation and immunomodulatory capacities [14]. Moreover, when transplanted in preclinical models, placenta-derived MSCs show mostly anti-inflammatory and anti-fibrotic effects [15]. In previous study, we have successfully isolated MSCs form the deciduas basalis of placenta (termed as PDB-MSCs) [16]. In order to test the feasibility of ${ }^{14} \mathrm{C}$ labeled thymidine as the potential tracker for MSCs tracking and to investigate the bio-distribution of PDB-MSCs after implantation, PDB-MSCs was labeled with ${ }^{14} \mathrm{C}-\mathrm{TdR}$ and then injected into the nude mice via the caudal vein for bio-distribution study.

\section{Results}

\section{Determination of the optimal ${ }^{14} \mathrm{C}-\mathrm{TdR}$ labeling concentration for PDB-MSCs}

To determine the optimal concentration, the labeling efficiency of different concentrations of ${ }^{14} \mathrm{C}$-TdR was analyzed after incubation with PDB-MSCs for $72 \mathrm{~h}$. As shown in Fig. 1a, the uptake of ${ }^{14} \mathrm{C}-\mathrm{TdR}$, represented as disintegrations per minute $(\mathrm{dpm})$ per cell, increased in a dose-dependent manner; unlabeled, $0.2,1$ and $5 \mu \mathrm{Ci}$-labeled groups resulted in $0,0.0481 \pm 0.006,0.131 \pm 0.009$ and $0.217 \pm 0.015 \mathrm{dpm} /$ cell, respectively (Fig. 1a). However, increasing concentrations of ${ }^{14} \mathrm{C}-\mathrm{TdR}$ administration were associated with the decreasing of total uptake efficiency (determined as the percentage of absorbed ${ }^{14} \mathrm{C}$-TdR versus total treatment dose) of PDB-MSCs because of limited absorption ability; $0.2 \mu \mathrm{Ci}, 1 \mu \mathrm{Ci}$ and $5 \mu \mathrm{Ci}$ treated groups resulted in $21.7 \pm 2.88 \%, 9.45 \pm$ $0.66 \%$ and $2.75 \pm 0.19 \%$ uptake, respectively (Fig. 1b). Moreover, the effect of different concentrations of ${ }^{14} \mathrm{C}$ TdR on PDB-MSCs proliferation was investigated and CCK-8 was used to assess cell growth rate. As shown in Fig. 1c, there was no statistical difference in the growth rate between the control group and those labeled with 0.2 and $1 \mu \mathrm{Ci}$ from day 3 to day 7 ( $P>0.05$ vs. control). However, a significant inhibition of proliferation was recorded in the group labeled with $5 \mu \mathrm{Ci}$ with the lowest growth rate during the 7 -day period $(P<0.01$ vs. control). These findings suggested that radiotoxicity occurred when the dose was higher than $1 \mu \mathrm{Ci}$.

Hence, considering the long-term safety and labeling sensitivity, even though both $0.2 \mu \mathrm{Ci}$ and $1 \mu \mathrm{Ci}$ did not inhibit the cellular proliferation, $1 \mu \mathrm{Ci}$ was the optimal concentration for PDB-MSCs labeling owing to its higher radioactivity $(0.131 \pm 0.009 \mathrm{dpm} /$ cell $)$. This concentration would increase the signal intensity during detection and thus was used in the subsequent experiments.

\section{Biological characteristics of ${ }^{14} \mathrm{C}$-TdR-labeled PDB-MSCs}

In order to understand the effects of ${ }^{14} \mathrm{C}$ - TdR labeling on the biological characteristics of PDB-MSCs, the morphology, differentiation, colony-forming abilities, karyotype, and cell cycle were analyzed.

As shown in Fig. 2a, PDB-MSCs labeled with $1 \mu \mathrm{Ci}$ displayed a similar fibroblastic and spindle-shaped morphology, similar to that of unlabeled PDB-MSCs. After culture with specific induction medium, labeled PDB-MSCs were positive for Alizarin Red and Oil Red $\mathrm{O}$, respectively, while those cultured in regular medium were negative (Fig. 2b). Additionally, there was not significant difference in the numbers of colony forming units (CFU) between the labeled and unlabeled groups: the number of unlabeled group was $583 \pm 32.5$ and that of the labeled group was $557 \pm 20.1$ (Fig. 2c\&d). After cell cycle analysis (Fig. 2e), it was found that both of labeled and unlabeled PDB-MSCs displayed the highest percentage in G0/G1 phase without significant alteration (labeled group $74.67 \%$, unlabeled group $76.33 \%$ ). Furthermore, $1 \mu \mathrm{Ci}{ }^{14} \mathrm{C}-\mathrm{TdR}$ labeling did not change the karyotype of PDB-MSCs (Fig. 2f). Thus, the above data indicated that there was no obvious change in PDBMSCs after $1 \mu \mathrm{Ci}{ }^{14} \mathrm{C}$-TdR labeling.

\section{Bio-distribution of PDB-MSCs in nude mice}

At days 1, 2, 3, 5, 30 and 180 post injection, the radioactivity of each organ was measured following decay and background corrections, and data were represented as mean $\mathrm{dpm} / \mathrm{mg} \pm$ standard deviation (SD). At day 1 after injection, radioactivity was highest in the lung $(76.7 \pm$ $31.9 \mathrm{dpm} / \mathrm{mg}$ ) and it was detectable in the kidney, spleen, left femur and bone marrow (Fig. 3a); but it was not detected in the organs from the control group (radioactivities of the organs from control group had no significant difference with the background radioactivity). And the radioactivity in liver and stomach were noted at day 2 after injection.

The radioactivity of the kidney, spleen and lung were diminished with time and the signal in the kidney was disappeared on day 3. Dramatically, cell detection in the 


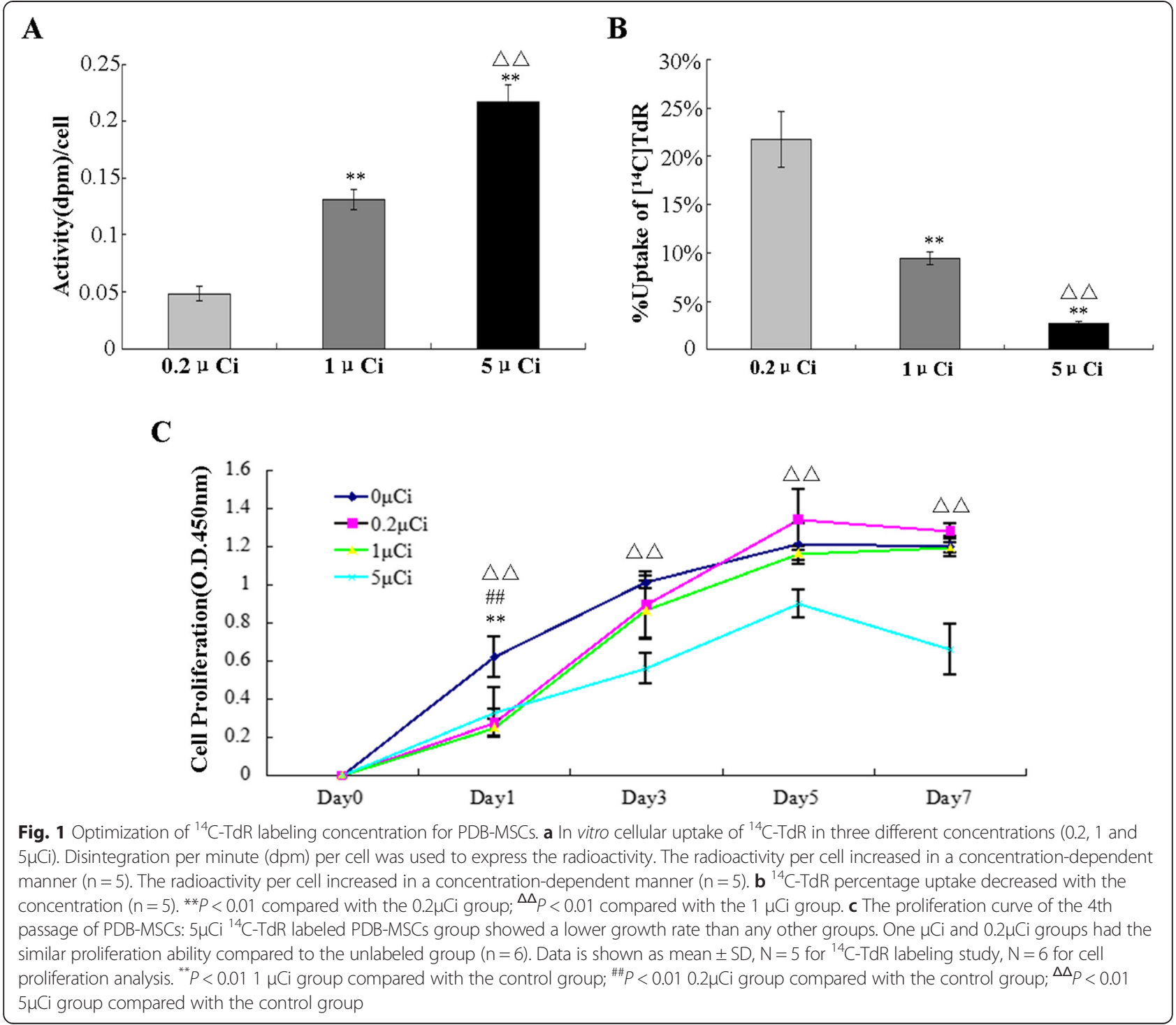

lung decreased from day 3 to day $5(42.3 \pm 12.3 \mathrm{dpm} / \mathrm{mg}$ to $7.64 \pm 1.59 \mathrm{dpm} / \mathrm{mg}$ ) (Fig. 3a). Beyond a decline on day 2 , a stable radioactivity was observed in the left femur and bone marrow which was even peaked on day $30(5.47 \pm 0.314 \mathrm{dpm} / \mathrm{mg})$ (Fig. 3a). The radioactivity value of liver increased from $2.05 \pm 0.257 \mathrm{dpm} / \mathrm{mg}$ (day 2) to $5.31 \pm 1.337 \mathrm{dpm} / \mathrm{mg}$ on day 3 ; and then it decreased gradually to $0.99 \pm 0.027 \mathrm{dpm} / \mathrm{mg}$ on day 30 . Similarly, radioactivity value of stomach experienced a rise from $3.55 \pm 0.797 \mathrm{dpm} / \mathrm{mg}$ (day 2) to $5.74 \pm 0.058 \mathrm{dpm} / \mathrm{mg}$ on day 3 and dropped to $1.41 \pm 0.102 \mathrm{dpm} / \mathrm{mg}$ on day 30 (Fig. 3a). No radioactivity was found in the heart, blood, brain and left femur muscle (Fig. 3a).

The number of infused cells in each organ on day 30 was calculated according to average radioactivity of infused cells. As shown in Fig. 3b, the left femur harvested with bone marrow had the highest number of infused
PDB-MSCs per gram $(41,725 \pm 2394 / \mathrm{g})$ and the number of cells in lung, spleen, stomach, and liver detected on day 30 were $32,748 \pm 3586,16,031 \pm 5640,10,763 \pm 777$, $7557 \pm 207$ per gram of tissue, respectively. As two mice died because of the feeding machine accident, only one mouse was used for organs collection on day 180. The radioactivity in the organs were mainly detected in liver (1.08 dpm/mg), lung $(3.82 \mathrm{dpm} / \mathrm{mg})$ and left femur harvested with bone marrow $(5.31 \mathrm{dpm} / \mathrm{mg})$, indicating that the infused PDB-MSCs were able to exist in bone tissue up to 6 months (Fig. 3a).

\section{Immunohistochemistry results}

Anti-human mitochondria antibody was used to detect the PDB-MSCs in the organs of nude mice. As shown in Fig. 4, negative result was found in control group (Fig. 4 a-e); at day 2 after injection, human cells were found in bone 


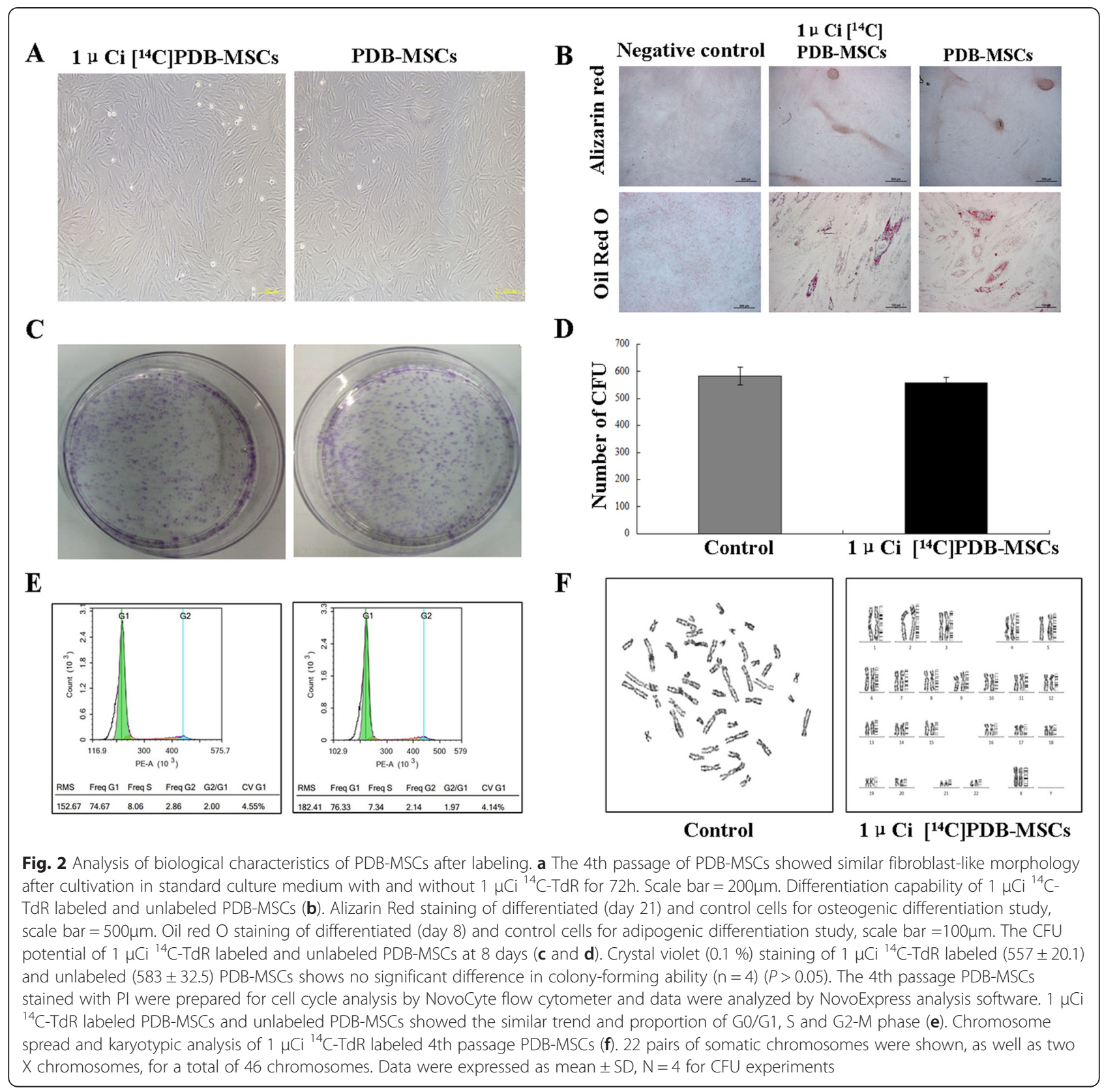

marrow, lung, liver, kidney and spleen, which was coincident with the radioactivity analysis results (Fig. $4 \mathrm{f}-\mathrm{j}$ ). Positive staining was only found in bone marrow, lung and liver on day 30 (Fig. 4 k-o). Thus, the same bio-distribution trend of PDB-MSCs in nude mice via IV injection was obtained after radioactivity and immunohistochemistry analysis.

\section{Discussion}

In this study, it was determined that PDB-MSCs labeled with $1 \mu \mathrm{Ci}{ }^{14} \mathrm{C}$-TdR did not have alterations in biological characteristics, and that after IV injection in nude mice, human PDB-MSCs were found to be presented in bone marrow, lung, liver, spleen and stomach.

At present, MRI, scintigraphic tracking, quantum dots (QDs), reporter gene labeling and optimal imaging, have been widely used for cell tracking. MRI is the most widely used due to its safety and the capacity of 3dimensional observation [17]. But several drawbacks were existed [18, 19]. For example, MRI cannot distinguish iron-labeled cells from the iron particles; second, the low sensitivity of MRI in clinical trails should be improved by up-regulating the magnetic field strengths, however, the toxic effects of MRI contrast agents on 


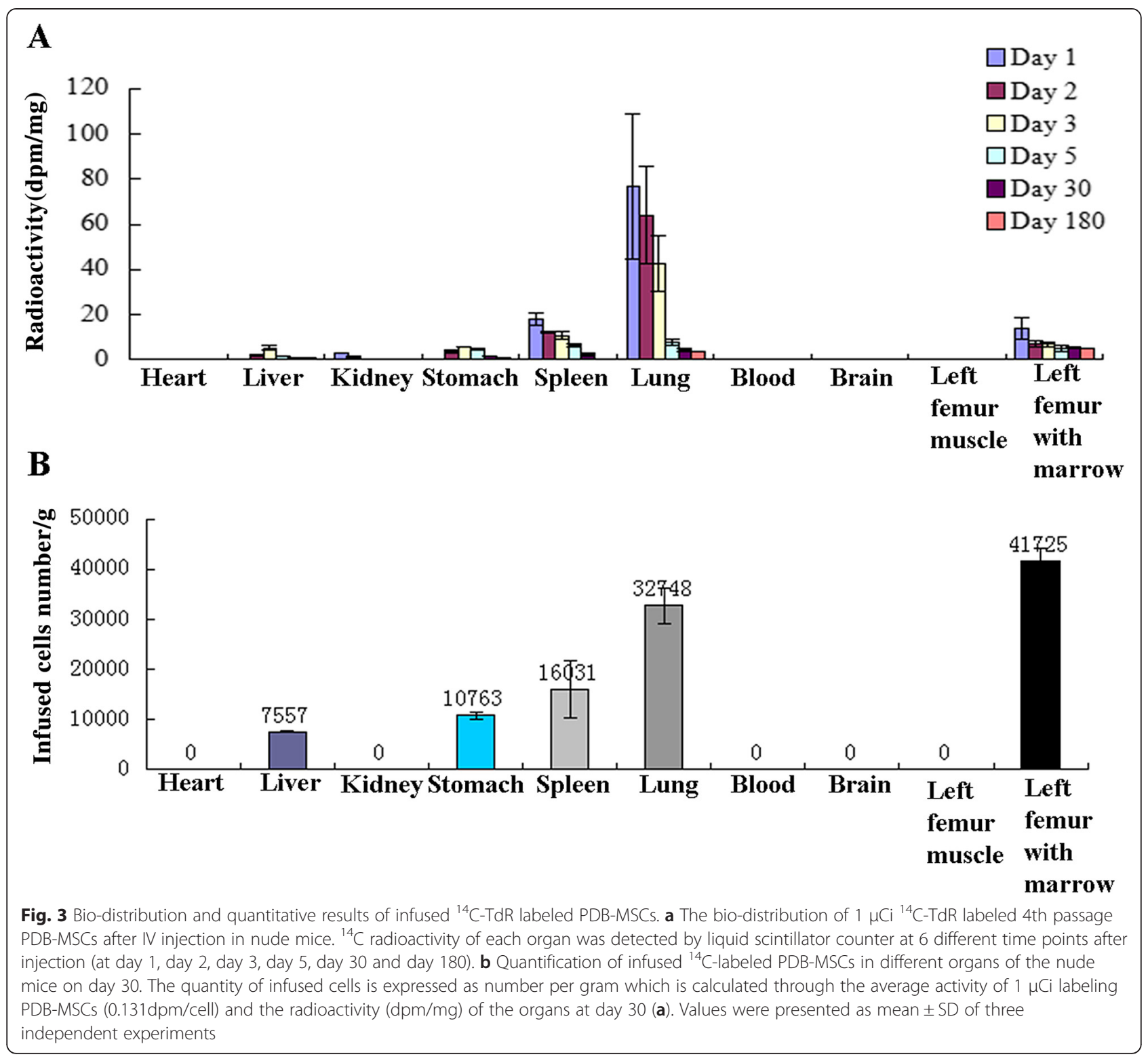

stem cells cannot be ignored [7, 19-22]. Another method for cell tracking is scintigraphy using radiolabeling materials: ${ }^{111}$ In-oxine, ${ }^{64} \mathrm{Cu}-\mathrm{PTSM}$ and ${ }^{124} \mathrm{I}$ FIAU, which can be visualized by positron emission tomography (PET) or single photon emission computed tomography (SPECT) and mainly applied in whole-body bio-distribution analysis $[8,19,23-29]$. This method is relatively highly sensitive and quantitative, however toxic effects on cell viability and photon attenuation by tissue should be considered [25, 30]. Also, QDs and reporter gene labeling induce cytotoxicity and require genetic modification or perturbation; additionally, quantification is difficult to be achieved [18]. Real time PCR (RT-PCR) is a valid alternative for the detection of human cells after xenografting, and had been utilized for detecting MSCs [28, 31-35] in mouse, rabbit and sheep models
[33, 36]; but this technique is a little bit complex and is not efficient enough to pick up small cell numbers from the large organs.

In this work, ${ }^{14} \mathrm{C}$ - $\mathrm{TdR}$ in the culture medium can be absorbed and incorporated in newly-synthesized DNA during cell replication, thus making it a stable tracer. As the aim of our research was to find a long-term, stable and quantitative method for PDB-MSCs tracking, hence comparison of the sensitivity of ${ }^{14} \mathrm{C}$-labeling method with other tracking methods was not performed, which should be investigated in future study.

After IV injection for $24 \mathrm{~h}$, radioactivity was mainly presented in lung, kidney and spleen, which was consistent with the findings from other groups after IV injection of MSCs [26-28]. It was reported that $99 \%$ of intravenously injected MSCs were cleared from the 


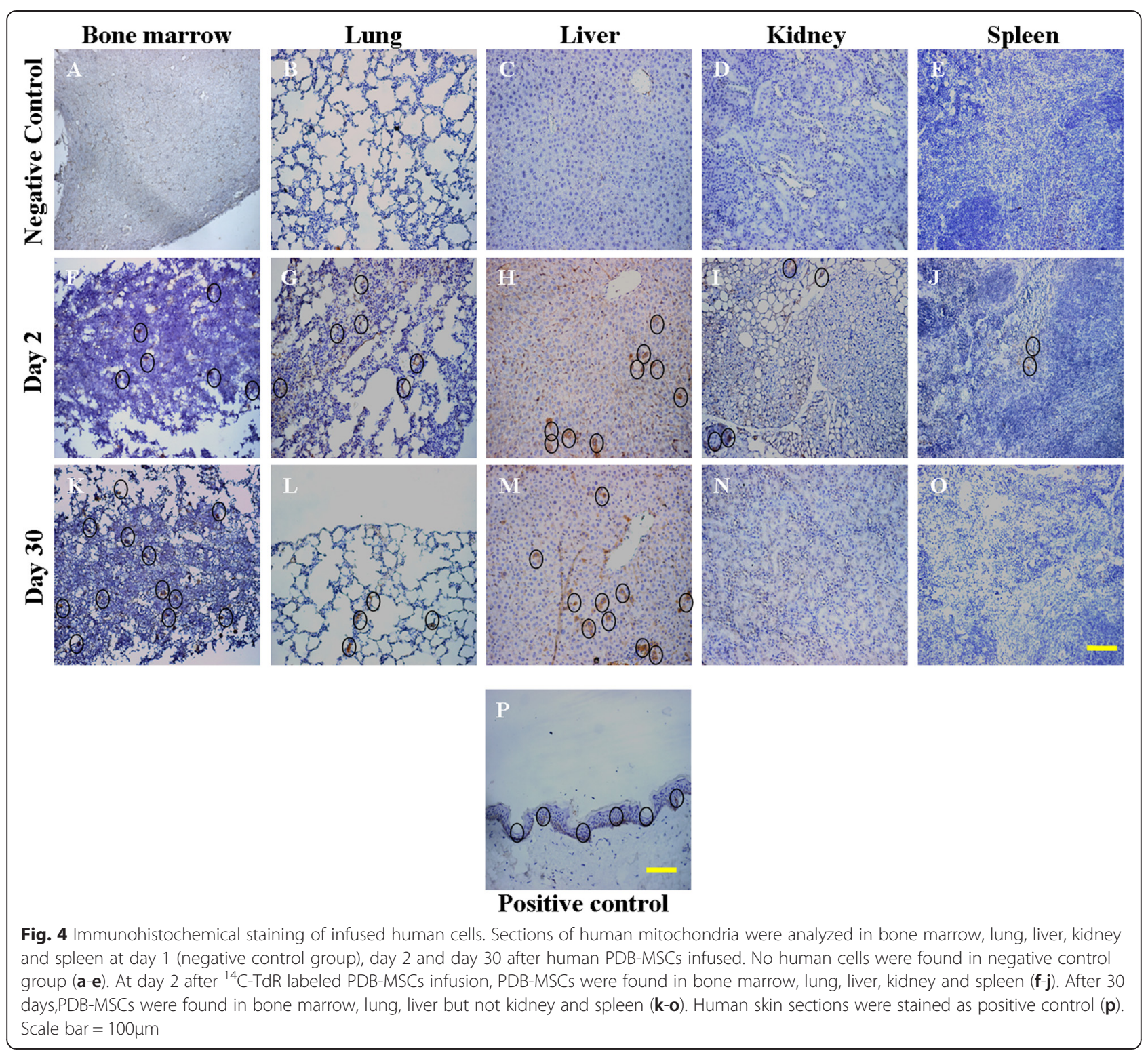

circulation system within 5 mins [37], thus it was reasonable that the radioactivity in blood was not noted after 24 $h$ in this study. No PDB-MSCs was found in the brain, heart and muscle; this result was conflicted with some previous findings $[9,26,27,34,36]$ which might be related to the variety of animal models, sources of MSCs and the trackers. It was demonstrated that the liver possessed a large proportion of infused cells [8, 26-29], which was not observed in our study until 5 days after infusion. The average diameter of human PDB-MSCs is $20-25 \mu \mathrm{m}$ (data not shown) and the diameter of capillaries in lungs is approximate $10 \sim 20 \mu \mathrm{m}$; therefore, most of the infused cells may accumulate in the filtering organs such as the lungs, liver and spleen. Since the lung is considered as the first organ after IV injection, many literatures suggested that majority of infused cells were initially trapped into lung for the first
24 h [9, 29] or earlier [27-29] after IV injection. Apart from the lung, bone marrow and spleen were detected with the highest radioactivity on day 30 . The possible explanation was that bone marrow is the major stem cell niche which might be the preferential migration target for MSCs. Spleen acts as a blood filter and it is an important part of immune system which might continuously filter cell debris or other incomplete catabolism products with ${ }^{14} \mathrm{C}$, thus increasing its radioactivity. Further studies need to be done to clarify the migration mechanism of intravenously injected MSCs, which is the major limitation in our study that we should acknowledge.

\section{Conclusion}

In summary, PDB-MSCs could be labeled with $1 \mu \mathrm{Ci}$ ${ }^{14} \mathrm{C}$-TdR successfully without significant changes in the 
proliferation, differentiation ability, CFU, karyotype and cell cycle profile; after intravenous injection, most of the ${ }^{14} \mathrm{C}$-TdR-labeled PDB-MSCs were initially located in the lung, spleen, stomach, femur and bone marrow and then the cells were quickly cleared in the first 5 days after injection; a small number of PDB-MSCs were detectable in liver, lung and left femur at 180 days after injection. Even though the cell number kept decreasing, this labeling method allowed the determination of the cell number presented at different time points. Therefore, $\left[2-{ }^{14} \mathrm{C}\right],{ }^{14} \mathrm{C}-\mathrm{TdR}$ may be a stable, long-term and quantitative cell tracker after MSCs implantation.

\section{Methods}

\section{Cell isolation and culture}

Human placenta samples were obtained from three healthy donor mothers with written informed consent. The study has been approved by the ethics committee of West China Hospital, Sichuan University. PDB-MSCs were isolated according to our previous report [16]. Briefly, decidua basalis was collected and washed in phosphate-buffered saline to remove residual blood. The samples were mechanically minced into small particles, and digested with $0.25 \%$ trypsin (Gibco, USA) and $0.1 \%$ collagenase IV (Invitrogen, USA) and 80U/ml DNAse I (Sigma, USA) for $30 \mathrm{mins}$ at $37^{\circ} \mathrm{C}$. Nucleated cells were concentrated by density gradient centrifugation (500 g for $30 \mathrm{mins}$ ), suspended in $5 \mathrm{ml}$ complete medium containing Dulbecco's modified Eagle's medium-High Glucose (DMEM-HG, Gibco, USA) with $10 \% \mathrm{v} / \mathrm{v}$ fetal bovine serum (FBS, Hyclone, South America) and $1 \%$ penicillin/streptomycin, and incubated in a $25 \mathrm{~cm}^{2}$ culture flask at $37{ }^{\circ} \mathrm{C}$ with $5 \% \mathrm{CO}_{2}$. After $70-80 \%$ confluence, cells were passaged at a dilution of 1:3. Cells from the 4th passage were used in the subsequent assays.

\section{${ }^{14} \mathrm{C}-\mathrm{TdR}$ labeling of PDB-MSCs}

To determine the optimal labeling condition, $3 \times 10^{5}$ PDB-MSCs were treated with different concentrations of ${ }^{14} \mathrm{C}-\mathrm{TdR}$ (PerkinElmer, Boston) $(0.2 \mu \mathrm{Ci}, 1 \mu \mathrm{Ci}, 5 \mu \mathrm{Ci})$ and incubated for $72 \mathrm{~h}$ at $37^{\circ} \mathrm{C}$ with $5 \% \mathrm{CO}_{2}$. After incubation, cells were washed with phosphate buffer saline (PBS, $\mathrm{pH}=7.4$ ) twice and harvested by $0.25 \%$ trypsin/ ethylene diamine tetraacetic acid (EDTA); the radioactivity of ${ }^{14} \mathrm{C}$ in labeled PDB-MSCs was measured by liquid scintillator counter (Beckman, USA) to estimate the uptake of each concentration.

\section{Cell proliferation}

Cell proliferation was assessed using CCK-8 Kit (Dojindo, Japan). Briefly, $2 \times 10^{3}$ PDB-MSCs and ${ }^{14} \mathrm{C}-$ TdR labeled PDB-MSCs with four concentrations, were plated in 96-well. Cell viability was monitored on days 0 ,
$1,3,5$ and 7, respectively. One hour after the addition of $10 \mu \mathrm{l}$ CCK-8 in $100 \mu \mathrm{l}$ culture medium optical density was determined using a spectrophotometer at $490 \mathrm{~nm}$ with background correction at $630 \mathrm{~nm}$.

\section{Cell differentiation}

To analyze the effect of ${ }^{14} \mathrm{C}$-TdR labeling on the multipotency of PDB-MSCs, osteogenic and adipogenic differentiation were performed in the unlabeled group and the $1 \mu \mathrm{Ci}{ }^{14} \mathrm{C}-\mathrm{TdR}$ labeled group. To induce osteogenic differentiation, radiolabeled and unlabeled PDB-MSCs were seeded in 6-well plates at a density of $5 \times 10^{3}$ cells/ well and cultured with osteogenic medium (complete medium with $10 \mathrm{mM} \beta$-glycerol phosphate (Sigma, Switzerland), $0.1 \mu \mathrm{M}$ dexamethasone (Sigma, USA) and $50 \mu \mathrm{g} / \mathrm{ml}$ ascorbate-2 (Sigma, USA)) for 21 days. The medium was changed every 3 days. After induction, cells were fixed with $75 \%$ ethanol for 20 mins, washed with PBS twice and stained with Alizarin red solution (Sigma, USA) for 30 mins.

For adipogenic induction, labeled and unlabeled cells were plated at a density of $5 \times 10^{3}$ cells/well and induced in the adipogenic medium consisting of $0.5 \mu \mathrm{M}$ isobutylmethylxanthine (Sigma, USA), $0.25 \mu \mathrm{M}$ dexamethasone (Sigma, USA), $10 \mu \mathrm{M}$ insulin (Sigma, USA) and $50 \mu \mathrm{M}$ indomethacin (Sigma, Germany). The medium was replaced every 3 days. After 8 days, cells were fixed with $10 \%$ formalin and stained for 30 mins with Oil red O solution (Sigma, USA) to visualize lipid vacuoles.

\section{CFU assay}

For the analysis of colony forming ability, labeled and unlabeled PDB-MSCs were plated at a density of 80 cells $/ \mathrm{cm}^{2}$ and cultured in completed medium. After 8 days, cells were washed with PBS, fixed with methanol for 5 mins and stained with $0.1 \%$ crystal violet (Sigma, USA) solution for 30 mins at $37{ }^{\circ} \mathrm{C}$. The number of MSCs clones was counted using the Image-Pro Plus 6.0 software (Media Cybernetics, USA).

\section{Karyotype analysis}

For karyotype analysis, ${ }^{14} \mathrm{C}$-labeled PDB-MSCs were treated with $10 \mu \mathrm{l} / \mathrm{mL}$ colcemid (Gibco, USA) for $2.5 \mathrm{~h}$, added to $1 \mathrm{ml} 0.075 \mathrm{M} \mathrm{KCl}$ solution for 20 mins and then fixed in $3 \mathrm{ml}$ Carnoy fixative for $30 \mathrm{mins}$ at $37{ }^{\circ} \mathrm{C}$. The cell specimens were made by standard air drying method. The G-band of labeled PDB-MSCs was analyzed by Metafer 4 Scanning System and the Ikaros Karyotype System (MetaSystems, USA).

\section{Cell cycle analysis}

For cell cycle analysis, $2 \times 10^{6}$ labeled and unlabeled PDB-MSCs were suspended in $70 \%$ alcohol and stored at $-4{ }^{\circ} \mathrm{C}$ overnight. After centrifugation and washing 
with PBS, cell pellets were incubated with $500 \mu$ l staining solution containing $50 \mu \mathrm{g} / \mathrm{ml}$ PI (Sigma, USA), $0.1 \mathrm{mg} /$ $\mathrm{ml}$ RNase A (Sigma, UK) and $0.05 \%$ Triton X-100 for 30 mins in the dark at $-4{ }^{\circ} \mathrm{C}$. DNA index was measured by NovoCyte Flow Cytometer (ACEA Biosciences, China) and data were analyzed by NovoExpress analysis software (ACEA Biosciences, China).

\section{In vivo infusion and bio-distribution}

All animal experiments were approved by the Institutional Animal Care and Use Committee of Sichuan University, and were carried out following Committee regulations and the Principles of Laboratory Animal Care formulated by the National Society for Medical Research. Four weekold female $B A L B / C$ nude mice $(n=21$, purchased from Chengdu Dashuo Laboratory Animal Limited Company), used in this study, were randomly divided into 7 groups. In the experimental groups, each mouse was injected with approximately $1 \times 10^{6} 1 \mu \mathrm{Ci}{ }^{14} \mathrm{C}$-TdR labeled PDB-MSCs via caudal vein and unlabeled PDB-MSCs served as the control group.

Mice injected with labeled PDB-MSCs were sacrificed on days $1,2,3,5,30$ and 180; mice injected with unlabeled PDB-MSCs were sacrificed on day 1. Organs including heart, liver, kidney, stomach, spleen, lung, blood, brain, left femur muscle, and the bone marrow from left femur (along with the femur itself) were harvested. Before the radioactivity assay, each organ was weighed and chemically digested with $100 \mu \mathrm{l} 30 \% \mathrm{H}_{2} \mathrm{O}_{2}$ (Kelong, Chengdu) and 200 $\mu$ l $60 \%$ perchloric acid (Kelong, Chengdu) for 30 mins at $80 \sim 90{ }^{\circ} \mathrm{C}$. During sample processing, the left femur containing both bone and the bone marrow was used en bloc since it was difficult to accurately weigh them. LS 6500 Scintillation Counter (Beckman, USA) was used to assess the radioactivity of each organ. Part of liver, lung and spleen, right femur and right kidney were prepared for immunohistochemical staining on day 2 and day 30, nude mice injected with $\mathrm{PBS}(\mathrm{pH}=7.4)$ were served as negative control group.

\section{Immunohistochemistry}

For immunohistochemical staining, samples were fixed with $4 \%$ paraformaldehyde for $48 \mathrm{~h}$ at room temperature. Bone samples were decalcified for 3 weeks in $10 \%$ EDTA ( $\mathrm{pH} 7.4$ ) with weekly changes, and then all the samples were embedded in paraffin. Anti-human mitochondria antibody (1:400; ab92824, Abcam, Cambridge, UK) were used for detecting human cells in nude mice. After dewaxed and rehydrated, sections $(4 \mu \mathrm{m})$ were blocked with $3 \%$ hydrogen peroxide for 15-20 mins at room temperature, followed by incubation with pepsin solution digest-all (Invitrogen, USA) for 20 mins at room temperature for bone sections antigen retrieval. Other organs sections were placed in trisodium citrate buffer $(\mathrm{pH}=6.0)$ for $40 \mathrm{mins}$ at $95{ }^{\circ} \mathrm{C}$. After naturally cooled to room temperature, the sections were washed with PBS for 3 times and incubated with the primary antibody solutions overnight at $4{ }^{\circ} \mathrm{C}$. Sections were rinsed with deionized water and then PBS, followed by 30 mins incubation with horse reddish peroxidase working solution (Gene Tech, Shanghai) at room temperature for 30 mins. After washed, 50-100 $\mu$ l 3,3'-diaminobenzidine (DAB) (Gene Tech, Shanghai) working solution was used for 510 mins at room temperature. The sections were then lightly counterstained with hematoxylin.

\section{Statistical analysis}

All data were expressed as mean \pm SD. Statistical analysis was performed using SPSS17.0 software (SPSS, USA). Results were analyzed with Student's $T$-test and $P<0.05$ were considered as statistically significant.

\section{Abbreviations}

MSCs: Mesenchymal stem cells; PDB-MSCs: Human placental deciduas basalis derived MSCs; C-TdR: Carbon radioisotope labeling thymidine; MRI: Magnetic resonance imaging scans; QDs: Quantum dots; ${ }^{3} \mathrm{H}-\mathrm{TdR}$ : Tritiated thymidine; dpm: Disintegrations per minute; CFU: Colony forming units; SD: Standard deviation; PET: Positron emission tomography; SPECT: Single photon emission computed tomography; RT-PCR: Real time PCR; DMEM-

HG: Dulbecco's modified Eagle's medium-High Glucose; FBS: Fetal bovine serum; PBS: Phosphate buffer saline; EDTA: Ethylene diamine tetraacetic acid; DAB: 3,3'-diaminobenzidine.

\section{Competing interests}

The authors declare that they have no competing interests.

\section{Authors' contributions}

LD, OP, Y-CH, MZ and C-GW designed the experiments. C-GW performed the study. J-CZ, C-QX, Y-ZH and BL were responsible for data acquisition. C-GW, $\mathrm{Y}-\mathrm{CH}, \mathrm{OP}, \mathrm{AS}$ and $\mathrm{Y}-\mathrm{ZH}$ wrote the paper. All authors read and approved the final manuscript for submission.

\section{Acknowledgements}

This work was financially supported by the National Natural Science Foundation (No.: 31070872, 31170948 and 31271049) and the National High Technology Research and Development Program of China (No: 2012AA020503).

\section{Author details}

'Laboratory of Stem Cell and Tissue Engineering, Regenerative Medicine Research Center, West China Hospital, Sichuan University, Chengdu, People's Republic of China. ${ }^{2}$ Centro di Ricerca E.Menni, Fondazione Poliambulanza, Brescia, Italy. ${ }^{3}$ West China School of Pharmacy, Sichuan University, Chengdu, People's Republic of China. ${ }^{4}$ Center Laboratory For Isotopy, West China Hospital, Sichuan University, Chengdu, People's Republic of China. ${ }^{5}$ Department of Orthopaedics and Traumatology, The University of Hong Kong, Hong Kong, SAR, People's Republic of China. 'Laboratory of Stem Cell and Tissue Engineering, State Key Laboratory of Biotherapy, West China Hospital, Sichuan University, Chengdu, People's Republic of China.

Received: 8 October 2014 Accepted: 29 May 2015

Published online: 13 June 2015

\section{References}

1. Kassem M, Abdallah BM. Human bone-marrow-derived mesenchymal stem cells: biological characteristics and potential role in therapy of degenerative diseases. Cell Tissue Res. 2008;331(1):157-63.

2. Dezawa M. Systematic neuronal and muscle induction systems in bone marrow stromal cells: the potential for tissue reconstruction in 
neurodegenerative and muscle degenerative diseases. Med Mol Morpho. 2008:41(1):14-9.

3. Tang Y, Shah K, Messerli SM, Snyder E, Breakefield X, Weissleder R. In vivo tracking of neural progenitor cell migration to glioblastomas. Hum Gene Ther. 2003;14(13):1247-54.

4. Jang $Y Y, Y e Z$, Cheng L. Molecular imaging and stem cell research. Mol Imaging. 2011;10(2):111-22.

5. Danner S, Benzin H, Vollbrandt T, Oder J, Richter A, Kruse C. Quantum dots do not alter the differentiation potential of pancreatic stem cells and are distributed randomly among daughter cells. Int J Cell Biol. 2013;2013.

6. Steyer GJ, Dong F, Kanodia L, Roy D, Penn M, Wilson DL. Detection and quantification of fluorescent cell clusters in cryo-imaging. Int J Biomed Imaging. 2012;2012:3.

7. Nohroudi K, Arnhold S, Berhorn T, Addicks K, Hoehn M, Himmelreich U. In vivo MRI stem cell tracking requires balancing of detection limit and cell viability. Cell Transplant. 2010;19(4):431-41.

8. Gao J, Dennis JE, Muzic RF, Lundberg M, Caplan Al. The dynamic in vivo distribution of bone marrow-derived mesenchymal stem cells after infusion. Cells Tissues Organs. 2001;169(1):12-20.

9. Feng SW, Lu XL, Liu ZS, Zhang YN, Liu TY, Li JL, et al. Dynamic distribution of bone marrow-derived mesenchymal stromal cells and change of pathology after infusing into mdx mice. Cytotherapy. 2008;10(3):254-64.

10. Vander Borght T, Pauwels S, Lambotte L, Beckers C. Rapidsynthesis of $2 \mathrm{C}$ radiolabelled thymidine: a potential tracer for measurement of liver regeneration Abstract. J Nuci Med. 1989;30:929.

11. Vander Borght T, Pauwels S, Lambotte $L$, Beckers $C$. In vivo determination of liver regeneration: the potential advantage of radiothymidine labelled in carbon 2 position. J Nuc/Med. 1989;30:815.

12. Cleaver JE. Thymidine metabolism and cell kinetics. Frontiers Biol. 1967;6:13-100

13. Shields AF, Lim K, Grierson J, Link J, Krohn KA. Utilization of labeled thymidine in DNA synthesis: studies for PET. J Nucl Med. 1990;31(3):337-42

14. Magatti M, De Munari S, Vertua E, Gibelli L, Wengler GS, Parolini O. Human amnion mesenchyme harbors cells with allogeneic T-cell suppression and stimulation capabilities. Stem Cells. 2008;26(1):182-92.

15. Parolini $\mathrm{O}$, Caruso M. Review: preclinical studies on placenta-derived cells and amniotic membrane: an update. Placenta. 2011;32:S186-95.

16. Huang YC, Yang ZM, Chen XH, Tan MY, Wang J, Li XQ, et al. Isolation of mesenchymal stem cells from human placental decidua basalis and resistance to hypoxia and serum deprivation. Stem Cell Rev. 2009;5(3):247-55.

17. Mirpour S, Gholamrezanezhad A. Clinical Stem Cell Imaging and In vivo Tracking. Stem Cells in Clinic and Research. Chapter 26. In: Ali G, editor. Tech. 1st ed. 2011. p. 637-56.

18. Zhang SJ, Wu JC. Comparison of imaging techniques for tracking cardiac stem cell therapy. J Nucl Med. 2007;48(12):1916-9.

19. Wolfs E, Verfaillie CM, Van Laere K, Deroose CM. Radiolabeling Strategies for Radionuclide Imaging of Stem Cells. Stem Cell Rev Rep. 2015;11(2):254-74.

20. Crabbe A, Vandeputte C, Dresselaers T, Sacido AA, Verdugo JM, Eyckmans J, et al. Effects of MRI contrast agents on the stem cell phenotype. Cell Transplant. 2010;19(8):919-36.

21. Kraitchman DL, Tatsumi M, Gilson WD, Ishimori T, Kedziorek D, Walczak P, et al. Dynamic imaging of allogeneic mesenchymal stem cells trafficking to myocardial infarction. Circulation. 2005;112(10):1451-61.

22. Boersma HH, Tromp SC, Hofstra L, Narula J. Stem cell tracking: reversing the silence of the lambs. J Nucl Med. 2005;46(2):200-3.

23. Kang WJ, Kang HJ, Kim HS, Chung JK, Lee MC, Lee DS. Tissue distribution of 18F-FDG-labeled peripheral hematopoietic stem cells after intracoronary administration in patients with myocardial infarction. J Nucl Med. 2006;47(8):1295-301.

24. Caveliers V, De Keulenaer G, Everaert H, Van Riet I, Van Camp G, Verheye S, et al. In vivo visualization of 111 In labeled CD133+ peripheral blood stem cells after intracoronary administration in patients with chronic ischemic heart disease. Q J Nucl Med Mol Imaging. 2007;51(1):61-6.

25. Frangioni $\mathrm{J}$, Hajjar RJ. In vivo tracking of stem cells for clinical trials in cardiovascular disease. Circulation. 2004;110(21):3378-83.

26. Mukherjee A, Tipnis S, Sarma HD, Ravindran G, Samuel G, Viswanathan C, et al. Radiolabeling of umbilical cord-derived mesenchymal stem cells for in vivo tracking. Cancer Biother Radiopharm. 2012;27(9):614-9.

27. Detante O, Moisan A, Dimastromatteo J, Richard MJ, Riou L, Grillon E, et al. Intravenous administration of 99mTc-HMPAO-labeled human mesenchymal stem cells after stroke: in vivo imaging and biodistribution. Cell Transplant. 2009;18(12):1369-79.

28. Park JJ, Lee TS, Son JJ, Chun KS, Song IH, Park YS, et al. Comparison of CellLabeling Methods with 124I-FIAU and 64Cu-PTSM for Cell Tracking Using Chronic Myelogenous Leukemia Cells Expressing HSV1-tk and Firefly Luciferase. Cancer Biother Radiopharm. 2012;27(10):719-28.

29. Gholamrezanezhad A, Mirpour S, Bagheri M, Mohamadnejad M, Alimoghaddam K, Abdolahzadeh $L$, et al. In vivo tracking of 111 In-oxine labeled mesenchymal stem cells following infusion in patients with advanced cirrhosis. Nucl Med Biol. 2011:38(7):961-7.

30. Gholamrezanezhad A, Mirpour S, Ardekani JM, Bagheri M, Alimoghadam K, Yarmand S, et al. Cytotoxicity of 111 In-oxine on mesenchymal stem cells: a time-dependent adverse effect. Nucl Med Commun. 2009;30(3):210-6.

31. Le Blanc K, Götherström C, Ringdén O, Hassan M, McMahon R, Horwitz E, et al. Fetal mesenchymal stem-cell engraftment in bone after in utero transplantation in a patient with severe osteogenesis imperfecta. Transplantation. 2005;79(11):1607-14.

32. Emmert MY, Weber B, Wolint $P$, Frauenfelder $T$, Zeisberger $S M$, Behr $L$, et al Intramyocardial transplantation and tracking of human mesenchymal stem cells in a novel intra-uterine pre-immune fetal sheep myocardial infarction model: a proof of concept study. PLoS One. 2013;8(3):e57759.

33. Meyerrose TE, De Ugarte DA, Hofling AA, Herrbrich PE, Cordonnier TD, Shultz LD, et al. In Vivo distribution of human adipose-derived Mesenchymal stem cells in novel xenotransplantation models. Stem Cells. 2007;25(1):220-7.

34. Bailo M, Soncini M, Vertua E, Signoroni PB, Sanzone S, Lombardi G, et al. Engraftment potential of human amnion and chorion cells derived from term placenta. Transplantation. 2004;78(10):1439-48.

35. Bensidhoum M, Chapel A, Francois S, Demarquay C, Mazurier C, Fouillard L, et al. Homing of in expanded Stro-1-or Stro-1+ human mesenchymal stem cells into the NOD/SCID mouse and their role in supporting human CD34 cell engraftment. Blood. 2004;103(9):3313-9.

36. Liechty KW, MacKenzie TC, Shaaban AF, Radu A, Moseley AM, Deans R, et al. Human mesenchymal stem cells engraft and demonstrate site-specific differentiation after in utero transplantation in sheep. Nat Med. 2000;6(11):1282-6.

37. Lee RH, Pulin AA, Seo MJ, Kota DJ, Ylostalo J, Larson BL, et al. Intravenous hMSCs improve myocardial infarction in mice because cells embolized in lung are activated to secrete the anti-inflammatory protein TSG-6. Cell Stem Cell. 2009;5(1):54-63.

\section{Submit your next manuscript to BioMed Central and take full advantage of:}

- Convenient online submission

- Thorough peer review

- No space constraints or color figure charges

- Immediate publication on acceptance

- Inclusion in PubMed, CAS, Scopus and Google Scholar

- Research which is freely available for redistribution

Submit your manuscript at www.biomedcentral.com/submit
C BioMed Central 